\title{
ES $\beta L$, AmpC and carbapenemase co-production in multi-drug resistant Gram-negative bacteria from HIV-infected patients in southwestern Nigeria
}

\author{
*Adeyemi, F. M., and Akinde, S. B. \\ Department of Microbiology, Faculty of Basic and Applied Sciences, \\ Osun State University, Osogbo, Nigeria \\ *Correspondence to: folasade.adeyemi@uniosun.edu.ng; +234 8034940747
}

\begin{abstract}
:
Background: The rising global emergence of Gram-negative bacteria (GNB) producing $\beta$-lactam hydrolysing enzymes in clinical infections constitutes a growing public health threat. This study investigated the occurrence of co-production of extended spectrum $\beta$-lactamase (ES $\beta L$ ), AmpC $\beta$-lactamases, and carbapenemases among GNB isolated from HIVinfected patients in two tertiary healthcare facilities in southwest Nigeria.

Methodology: A total of 115 GNB isolates previously recovered from HIV-infected patients at the Obafemi Awolowo University Teaching Hospitals Complex, Ile-Ife, and the State Specialist Hospital, Akure, were investigated. The isolates were characterized to species level with the Microbact 24E kit and screened for ES $\beta L$ production using the double-disc test (DDT) and combination disc methods, AmpC using modified Hodge test (MHT) and AmpC EDTA disc, and carbapenemase production using the MHT and EDTA disc test. Antibiotic susceptibility testing (AST) was performed by the Kirby-Bauer disc diffusion method.

Results: A total of 15 species of GNB were characterized. The AST profile of the isolates revealed high resistance rates to ampicillin $(94.5 \%)$, tetracycline $(74.5 \%)$, sulphamethoxazole-trimethoprim $(66.3 \%)$, and lowest resistance to imipenem (10.9\%). Multi-drug resistance (MDR) was observed in $93.6 \%$ while $98.8 \%$ of ES $\beta$, AmpC, and carbapenemase-producing isolates had multiple antibiotic resistance (MAR) indices $\geq 0.2$. ES $\beta$ L production was detected in $53.9 \%, A m p C$ in $20.9 \%$ and carbapenemase in $25.2 \%$ of the isolates. ES $\beta$, AmpC or carbapenemase or co-production of two or all three enzymes was detected in $80(69.6 \%)$ isolates, while only $10.0 \%$ produced all three enzymes.

Conclusion: The isolation of MDR bacteria and isolates co-producing $\beta$-lactam hydrolysing enzymes in immunocompromised individuals portend grave consequences. Routine screening for these enzymes in MDR bacteria will be highly essential to guide the institution of appropriate antibiotic therapy and infection control measures.
\end{abstract}

Keywords: ES $\beta$ L, AmpC, carbapenemase, HIV, MDR, clinical isolates, MHT, DDST

Received June 2, 2020; Revised June 24, 2020; Accepted June 30, 2020

Copyright 2021 AJCEM Open Access. This article is licensed and distributed under the terms of the Creative Commons Attrition 4.0 International License <a rel="license" href="http://creativecommons.org/licenses/by/4.0/", which permits unrestricted use, distribution and reproduction in any medium, provided credit is given to the original author(s) and the source. Editor-in-Chief: Prof. S. S. Taiwo

\section{Coproduction d'ES $\beta L$, AmpC et carbapénémase dans des bactéries Gram-négatives multirésistantes de patients infectés par le VIH dans le sud-ouest du Nigéria}

\author{
*Adeyemi, F. M., et Akinde, S. B. \\ Département de microbiologie, Faculté des sciences fondamentales et appliquées, \\ Université d'État d'Osun, Osogbo, Nigéria \\ *Correspondance avec: folasade.adeyemi@uniosun.edu.ng; +234 8034940747
}

\begin{abstract}
Abstrait:
Contexte: L'émergence mondiale croissante de bactéries à Gram négatif (GNB) produisant des enzymes d'hydrolyse de $\beta$-lactame dans les infections cliniques constitue une menace croissante pour la santé publique. Cette étude a examiné l'occurrence de la coproduction de $\beta$-lactamases à spectre étendu (ES $\beta L$ ), de $\beta$-lactamases AmpC et de
\end{abstract}


carbapénémases parmi les GNB isolés de patients infectés par le VIH dans deux établissements de santé tertiaires du sud-ouest du Nigéria.

Méthodologie: Un total de 115 isolats de GNB précédemment récupérés de patients infectés par le VIH au complexe hospitalier universitaire Obafemi Awolowo, Ile-Ife, et au State Specialist Hospital, Akure, ont été étudiés. Les isolats ont été caractérisés au niveau des espèces avec le kit Microbact 24E et criblés pour la production d'ES $\beta L$ en utilisant le test à double disque (DDT) et les méthodes de disques combinés, AmpC en utilisant le test Hodge modifié (MHT) et le disque AmpC EDTA, et la production de carbapénémase en utilisant le MHT et test de disque EDTA. Le test de sensibilité aux antibiotiques (AST) a été effectué par la méthode de diffusion de disque de Kirby-Bauer Résultats: Un total de 15 espèces de GNB ont été caractérisées. Le profil AST des isolats a révélé des taux de résistance élevés à I'ampicilline $(94,5 \%)$, à la tétracycline $(74,5 \%)$, au sulfaméthoxazole-triméthoprime (66,3\%) et à la plus faible résistance à l'imipénème $(10,9 \%)$. Une résistance à plusieurs médicaments (MDR) a été observée dans $93,6 \%$ tandis que $98,8 \%$ des isolats producteurs d'ES $\beta L$, AmpC et carbapénémase avaient de multiples indices de résistance aux antibiotiques (MAR) $\geq 0,2$. La production d'ES $\beta$ L a été détectée dans 53,9\%, AmpC dans 20,9\% et carbapénémase dans $25,2 \%$ des isolats. ES $\beta$, AmpC ou carbapénémase ou la coproduction de deux ou des trois enzymes a été détectée dans 80 isolats $(69,6 \%)$, tandis que seulement $10,0 \%$ ont produit les trois enzymes. Conclusion: L'isolement des bactéries MDR et des isolats co-producteurs d'enzymes d'hydrolyse des $\beta$-lactamines chez les individus immunodéprimés laisse présager de graves conséquences. Le dépistage systématique de ces enzymes dans les bactéries MDR sera très essentiel pour guider la mise en place d'une antibiothérapie appropriée et de mesures de contrôle des infections.

Mots-clés: ESßL, AmpC, carbapénémase, VIH, MDR, isolats cliniques, MHT, DDST

\section{Introduction:}

The use of antibiotics for the treatment of infections in humans and livestock usually result in the selection of pathogenic bacteria which become multiply resistant to them $(1,2)$. Several strains of Gram-negative bacteria (GNB) are becoming resistant to practically all the commonly available antibacterial agents $(3,4)$. Prominent among these GNB are the extendedspectrum $\beta$-lactamase (ES $\beta L$ ) enterobacteria (5). ES $\beta$ Ls are extended-spectrum $\beta$-lactamases that are capable of conferring bacterial resistance to the penicillins, first-, second-, and third-generation cephalosporins, as well as to aztreonam except cephamycins or carbapenems (6-9). ES $\beta$ Ls are mutants of TEM-1, TEM-2, and SHV-1 which act by hydrolysing $\beta$-lactam antibiotics but are inhibited by $\beta$-lactamase inhibitors such as clavulanic acid (10), sulbactam, and tazobactam (11). However, the CTX-M type ES $\beta$ LS have become more broadly distributed and globally prevalent (12-14).

AmpC $\beta$-lactamases are clinically significant because they may confer resistance to penicillins, cephalosporins (15), oxyimino-cephalosporins, cephamycins (16), and monobactams. Unlike $E S \beta L, A m p C \beta$-lactamase activity is not affected by clavulanic acid (17). Although reported with increasing frequency in clinical isolates, the actual occurrence rate of plasmidmediated AmpC $\beta$-lactamases in Enterobacteriaceae remains unknown as many laboratories have difficulty in detecting these enzymes in clinical isolates (18).

Carbapenems are powerful, broad-spectrum antibiotics, which are often considered to be the last line of defence in the treatment of infections caused by multidrug-resistant (MDR) GNB (19) because they are stable even in the presence of the extended-spectrum and AmpC $\beta$-lactamases. Carbapenemases are ES $\beta$ Ls produced by resistant bacteria strains (20) which possess hydrolytic capacity against almost all $\beta$ lactam antibiotics including carbapenems, and constitute the most versatile family of $\beta$-lactamases belonging to molecular classes- $A, B$ and $D$. $E S \beta L$ and carbapenemase producing bacteria have become significant threats to patients in the hospital (21) and long-term care facilities as well as to immuno-compromised persons in the community. Worldwide, there is a rapid increase in the prevalence of $E S \beta L$, AmpC, and carbapenemase producing members of the family Enterobacteriaceae (21-27), and infections caused by them are associated with increased morbidity, mortality, and health care costs $(21,28-31)$. Significant increase in the incidence of ES $\beta L$-related infections has been reported by various authors from around the world (32-36).

The increasing use of carbapenems to treat infections caused by ES $\beta$ L-producing GNB is creating a ripple effect by causing increase in the prevalence of carbapenemase-producing bacteria. The screening and probable detection of ES $\beta L$ production among bacteria isolates from immuno-compro- mised individuals as the case with HIV-infected patients, is of tremendous clinical significance because this may be an epidemiologic marker of colonisation (37), which may invariably portend severe implications in this group of patients. Again, these organisms exhibit co-resistance to many other classes of antibiotics because plasmids that encode $E S \beta L$ genes most frequently carry genes encoding resistance to other drug classes, leading to failure in the treatment regimen and making therapeutic options limited (38). 
There are various studies on the prevalence of ES $\beta L$ producing bacteria that have been conducted in different parts of Nigeria $(7,39-46)$ with rates varying between $7.5 \%$ $(43,47)$ and $58.6 \%(42)$, depending on the samples from which the isolates were obtained. A systematic review by Manenzhe et al., (48) reported that carbapenemase producers occur widely in Africa and have been reported in Nigeria (48). Le Terrier et al., (49) also recently reported the preponderance of carbapenemaseproducers in a Nigerian environment. Because of this, routine monitoring of clinical isolates for these traits with particular emphasis on patients who are immunocompromised is important. In this study, we evaluated the production of ES $\beta L$, AmpC, and carbapenemase among selected GNB isolates recovered from HIV-infected patients in two tertiary healthcare facilities in southwestern Nigeria using two phenotypic screening methods for the detection of each enzyme.

\section{Materials and method:}

Gram-negative isolates from participants:

The GNB isolates $(n=115)$ investigated in this study were randomly selected from a collection of 316 GNB cultured from skin, throat, and rectal swabs of HIV seropositive patients in our previous study $(50,51)$. The patients were recruited from two hospitals; Obafemi Awolowo University Teaching Hospitals Complex, Ile-Ife, and State Specialist Hospital, Akure, Ondo State, over a period of 18 months. Where two isolates from one patient were included, the strains were unique regarding species identification or resistance pattern.

A preformed questionnaire indicating participant demographic information including age, gender, and other relevant information was used to collate data. Approval for the study was obtained from the Ethical Review Board of the Obafemi Awolowo University Teaching Hospital, Ile-Ife and the Management Board of Ondo State Specialist Hospital, Akure.

\section{Identification of the GNB isolates}

The isolates, preserved in TSB with $15 \%$ glycerol broth at $-20^{\circ} \mathrm{C}$, were sub-cultured and purified on MacConkey agar (Oxoid, UK) for identification to species level. The inoculum was prepared by picking one or two well-isolated colonies and emulsifying in $5 \mathrm{ml}$ Ringer's solution (Oxoid, UK). The Microbact ${ }^{T M}$ GNB 24E system was inoculated according to the manufacturer's instructions and incubated at $35 \pm 2{ }^{\circ} \mathrm{C}$ for $18-24$ hours for oxidase-negative strains and 48 hours for oxidase-positive strains of the GNB. The wells were observed for colour change following the addition of appropriate reagents in line with the manufacturer's instruction. Each well was ascribed a numerical value indicating either a positive or negative reaction which was converted to a 9-digit code for final identification with the Microbact ${ }^{\mathrm{TM}}$ identification software version 2.04. The acceptable species identification was $\geq 80.0 \%$ and $\leq 99.9 \%$.

\section{Antibiotic susceptibility testing of GNB isolates}

An in vitro antibiotic susceptibility assay was carried out on 110 of the 115 GNB isolates using the Kirby-Bauer disc diffusion method. Eleven antibiotics (Oxoid, UK) selected based on their frequent use in research and clinical therapy included ampicillin $(10 \mu \mathrm{g})$, chloramphenicol $(30 \mu \mathrm{g})$, colistin $(10 \mu \mathrm{g})$, gentamicin $(10$ $\mu \mathrm{g})$, imipenem $(10 \mu \mathrm{g})$, nalidixic acid $(30 \mu \mathrm{g})$, nitrofurantoin $(300 \mu \mathrm{g})$, piperacillin $(30 \mu \mathrm{g})$, piperacillin/tazobactam $(36 \mu \mathrm{g})$, tetracycline (30 $\mu \mathrm{g})$ and trimethoprim/sulfamethoxazole $(25 \mu \mathrm{g})$.

Quality control was performed using Enterobacter aerogenes ATCC 13048 to confirm the consistency of materials, methods, and results. Interpretation of results as either susceptible, intermediate, or resistant was done using the zone diameter breakpoints recommended by Clinical and Laboratory Standards Institute (52). MDR pattern among the GNB isolates was defined as resistance to $\geq 1$ agent in $\geq 3$ antibiotic classes (53). Multiple antibiotic resistance (MAR) index for each isolate was evaluated by dividing the number of antibiotics to which isolate was resistant by the total number of antibiotics against which the bacteria isolate was tested (54).

\section{Detection of ES $\beta$ L, AmpC, and carbapenemase in GNB isolates}

\section{Phenotypic ES $\beta L$ screening:}

Screening for ES $\beta L$ production was done using two methods: the double-disc synergy test (DDST) and the combination disc test methods. DDST was carried out, as described by Jarlier et al., (55). Using a sterile cotton-tipped applicator, Mueller-Hinton agar was inoculated with standardised test organism (0.5 McFarland turbidity standard) in Ringer's solution to give a semi-confluent growth. Discs containing $30 \mu \mathrm{g}$ each of aztreonam, ceftriaxone, cefotaxime, and ceftazidime, were placed $30 \mathrm{~mm}$ apart (centre to centre) around a disc containing amoxicillin (20 $\mu \mathrm{g})$ plus clavulanic acid $(10 \mu \mathrm{g})$ on the agar surface, incubated at $35 \pm 2{ }^{\circ} \mathrm{C}$ for $18-24$ hours. Inhibition zone enhancement which indicates synergy between clavulanic acid and any one of test antibiotics, was regarded as presumptive ES $\beta$ L production. Klebsiella pneumoniae ATCC 700603 and Escherichia coli ATCC 25922 strains 
served as positive and negative control strains respectively.

The combination disc test was performed using disc pairs containing cephalosporin (cefotaxime, ceftazidime, and cefpodoxime) with and without clavulanic acid in each case (56). Inoculation was carried out as described for DDST. The paired discs were placed on the inoculated plates with a distance of at least $25 \mathrm{~mm}$ separating them. The zones of inhibition were measured following overnight incubation at $35 \pm 2{ }^{\circ} \mathrm{C}$. Inhibition zone of $\geq 5 \mathrm{~mm}$ or expansion by $50 \%$ around the combination disc (cephalosporin with clavulanic acid) compared to the cephalosporin disc alone was indicative of ES $\beta L$ production (56).

\section{AmpC $\beta$-lactamase detection:}

Screening for AmpC $\beta$-lactamase production was done by the AmpC disc test and modified Hodge test (MHT). AmpC disc test was carried out as described by Black et al., (57) with modification. AmpC discs were prepared inhouse by applying $20 \mu \mathrm{l}$ of a $0.5 \mathrm{M}$ Tris-EDTA to sterile filter paper discs and dried, then rehydrated with $20 \mu \mathrm{l}$ saline just before use. Cefoxitin susceptible Escherichia coli ATCC 8739 was used for lawn preparation on Mueller-Hinton agar. Cefoxitin disc $(30 \mu \mathrm{g})$ was placed on the inoculated media next to AmpC disc inoculated with the test isolate, with the inoculated disc face in contact with the agar surface. After overnight incubation at $35 \pm 2^{\circ} \mathrm{C}$, an indentation or a flattening of the zone of inhibition, indicating enzymatic inactivation of cefoxitin was recorded as a positive result, while the absence of a distortion was recorded as a negative result.

For the MHT test, a suspension of the cefoxitin susceptible strain of $E$. coli ATCC 8739 was prepared, diluted 1:10 with physiological saline, and swabbed across a Mueller Hinton plate with a sterile cotton-tipped applicator. A $30 \mu \mathrm{g}$ cefoxitin disc was placed at the centre of the test plate, and the test isolate was streaked in a straight line from the edge of the disc towards the edge of the plate. The plate was incubated overnight at $35 \pm 2{ }^{\circ} \mathrm{C}$. A positive test was indicated by the growth of the E. coli ATCC 8739 along the line of streak of the test isolate towards the cefoxitin disc, while there was no growth of the $E$. coli on the line of streak in a negative result.

\section{Carbapenemase production:}

The phenotypic screening for carbapenemase production was carried out using the $\mathrm{MHT}$ and the EDTA disc methods. The MHT was as described for $10 \mu \mathrm{g}$ imipenem but opposed to cefoxitin for AmpC screening. The E. coli strain ATCC 8739 used was also susceptible to imipenem. A positive test was indicated by a clover leaf-like indentation of the E. coli 8739 growing along the growth streak of the test organism within the disc diffusion zone, while a negative test showed no growth of the $E$. coli 8739 along the test organism growth streak within the disc diffusion zone. Quality control of the carbapenem discs was performed according to CLSI guidelines (52) by running MHT positive Klebsiella pneumoniae ATCC 1705 and MHT negative Klebsiella pneumoniae ATCC 1706 with each batch of the test.

For the EDTA disc test, a 0.5M EDTA solution was first prepared by dissolving $9.36 \mathrm{~g}$ of EDTA and $6.05 \mathrm{~g}$ of TRIS base in $50 \mathrm{ml}$ of distilled water in a $50 \mathrm{ml}$ volumetric flask, and its $\mathrm{pH}$ was adjusted to 8.0 by using $\mathrm{NaOH}$. A $1 \mu \mathrm{l}$ of the $0.5 \mathrm{M}$ Tris-EDTA solutions was then dispensed onto sterile plain discs and the discs were used immediately. A lawn of the test isolate was plated on Mueller Hinton agar plate using a sterile cotton-tipped applicator and an imipenem disc $(10 \mu \mathrm{g})$ was placed in the centre of the plate with sterile forceps. The Tris-EDTA discs inoculated with colonies of the test strain were placed about $1 \mathrm{~mm}$ to the imipenem disc with the inoculated side touching the agar. The plates were incubated at $35 \pm 2{ }^{\circ} \mathrm{C}$ in ambient air for 16-24 hours. Indentation of the inhibition zone around the inoculated disc was indicative of the production of carbapenem-hydrolysing enzyme (positive test).

\section{Data analysis}

Data on identification, susceptibility and enzyme production of the GNB isolates were analysed using the Statistical Package for the Social Sciences (SPSS) version 23.0, and results presented with frequency distribution tables and simple graphs.

\section{Results:}

The identification and distribution pattern of the 115 GNB bacteria isolates randomly selected for the study is shown in Table 1 , with 80 (69.6\%) oxidase-positive and 35 (30.4\%) oxidase-negative. The GNB isolates were characterized into 15 species (5 species for oxidasepositive and 10 species for oxidase-negative). A total of $80(69.6 \%)$ isolates produced $E S \beta L$, AmpC, carbapenemase, or co-produced either two or three of the enzymes. 
Table 1. Distribution of selected Gram-negative isolates from HIV seropositive patients

\begin{tabular}{|c|c|c|c|c|}
\hline \multirow[t]{2}{*}{ Isolate identity } & \multicolumn{4}{|c|}{ Frequency distribution [number (\%)] } \\
\hline & $\begin{array}{l}\text { Isolates from } \\
\text { Skin }\end{array}$ & $\begin{array}{c}\text { Isolates from } \\
\text { Throat }\end{array}$ & $\begin{array}{l}\text { Isolates from } \\
\text { Rectal Swabs }\end{array}$ & Total isolates \\
\hline \multicolumn{5}{|l|}{ Oxidase Positive } \\
\hline Actinobacillus sp. & $1(1.2)$ & $0(0.0)$ & $1(4.5)$ & $2(1.7)$ \\
\hline Pseudomonas fluorescens 25 & $6(7.3)$ & $0(0.0)$ & $0(0.0)$ & $6(5.2)$ \\
\hline Burkholderia pseudomallei & $10(12.2)$ & $1(9.1)$ & $6(27.3)$ & $17(14.8)$ \\
\hline Aeromonas hydrophila & $17(20.7)$ & $1(9.1)$ & $3(13.6)$ & $21(18.2)$ \\
\hline Burkholderia cepacia & $24(29.3)$ & $4(36.3)$ & $6(27.3)$ & $34(29.5)$ \\
\hline \multicolumn{5}{|l|}{ Oxidase Negative } \\
\hline Citrobacter freundii & $1(1.2)$ & $0(0.0)$ & $0(0.0)$ & $1(0.9)$ \\
\hline Citrobacter youngae & $1(1.2)$ & $0(0.0)$ & $0(0.0)$ & $1(0.9)$ \\
\hline Morganella morganii biogp 1 & $1(1.2)$ & $0(0.0)$ & $0(0.0)$ & $1(0.9)$ \\
\hline Photorhabdus asymbiotica & $1(1.2)$ & $0(0.0)$ & $0(0.0)$ & $1(0.9)$ \\
\hline Pragia fontium & $1(1.2)$ & $0(0.0)$ & $0(0.0)$ & $1(0.9)$ \\
\hline Serratia marcescens & $1(1.2)$ & $0(0.0)$ & $0(0.0)$ & $1(0.9)$ \\
\hline Proteus vulgaris & $2(2.4)$ & $1(9.1)$ & $0(0.0)$ & $3(2.6)$ \\
\hline Photorhabdus luminescens 25C & $1(1.2)$ & $1(9.1)$ & $1(4.5)$ & $3(2.6)$ \\
\hline Proteus mirabilis & $7(8.5)$ & $1(9.1)$ & $2(9.1)$ & $10(8.7)$ \\
\hline Pantoea agglomerans complex & $8(9.8)$ & $2(18.2)$ & $3(13.6)$ & $13(11.3)$ \\
\hline Total & $82(71.3)$ & $11(9.6)$ & $22(19.1)$ & 115 \\
\hline
\end{tabular}

Antibiotic resistance profiles of GNB isolates Out of the 115 GNB isolates, AST was performed only on 110 . The AST profile of the isolates revealed that $94.5 \%(104 / 110)$ were resistant to ampicillin, $74.5 \%$ to tetracycline, and $66.3 \%$ to sulfamethoxazole-trimethoprim. The isolates exhibited lowest resistance rate to imipenem at $10.9 \%(12 / 110)$, closely followed by piperacillin/tazobactam at $13.6 \%$ and gentamicin at $15.5 \%$ (Table 2 ).

For the 80 enzyme-producing isolates, the least resistance rate was observed with piperacillin/tazobactam (11.3\%), followed by imipenem (13.8\%) and gentamicin (17.5\%) while the highest resistance was to ampicillin, tetracycline, and sulfamethoxazole-trimethoprim at $93.8 \%, 72.5 \%$, and $70.0 \%$ respectively (Table 3).

All the isolates were resistant to at least one antibiotic and none was sensitive to all the antibiotics. Only $1(0.9 \%)$ of the isolates tested was resistant to only one antibiotic and 6 (5.4\%) to only two antibiotics. This implied a high level of MDR as $93.6 \%(103 / 110)$ were resistant to more than three classes of antibiotics (Fig 1).
For ESßL, AmpC, and carbapenemaseproducing strains, $82.5 \%(66 / 80)$ isolates were resistant to $\geq 4$ classes of antibiotics. Only one isolate $(1.25 \%)$, Aeromonas hydrophila was resistant to one antibiotic class (ampicillin), 6 isolates $(7.5 \%)$ to two classes, and 7 isolates $(8.75 \%)$ to three antibiotic classes. The multiple antibiotic resistance index (MAR index) (Fig 2) showed that $97.3 \%$ of the total number of isolates and $98.8 \%$ of ES $\beta$, AmpC, and carbapenemase-producing strains had MAR indices $\geq$ 0.2 .

Co-production of ES $\beta \mathrm{L}, \mathrm{AmpC}$, and carbapenemmase in GNB isolates

\section{Pattern of ES $\beta$ L production}

Using either one or both ES $\beta L$ screening methods, $53.9 \%(62 / 115)$ of the GNB were ES $\beta$ L producers; $32(27.8 \%)$ were detected by the combination disc method (10 Burkholderia cepacia, 7 Aeromonas hydrophila, 5 Burkholderia pseudomallei, 5 Pantoea agglomerans complex, 3 Proteus mirabilis, and 1 each of Pseudomonas fluorescens 25 and Serratia marcescens) 
Table 2: Antibiotic resistance profile of selected Gram-negative isolates from HIV seropositive patients

\begin{tabular}{|c|c|c|c|c|c|c|c|c|c|c|c|c|}
\hline \multirow[t]{2}{*}{ Isolate identity } & \multirow{2}{*}{$\begin{array}{l}\text { Number } \\
\text { tested }\end{array}$} & \multicolumn{11}{|c|}{ Resistance profile (number of isolates) } \\
\hline & & AMP & PIP & PTZ & IPM & GEN & $\mathrm{CHL}$ & NA & NFT & TET & COL & SXT \\
\hline \multicolumn{13}{|l|}{ Oxidase Positive } \\
\hline Actinobacillus sp. & 2 & 2 & 0 & 0 & 0 & 1 & 0 & 1 & 1 & 1 & 1 & 1 \\
\hline Pseudomonas fluorescens 25 & 6 & 5 & 4 & 2 & 0 & 0 & 3 & 2 & 5 & 3 & 0 & 3 \\
\hline Burkholderia pseudomallei & 16 & 16 & 6 & 0 & 1 & 3 & 10 & 4 & 8 & 13 & 7 & 12 \\
\hline Aeromonas hydrophila & 20 & 18 & 13 & 5 & 2 & 3 & 10 & 8 & 10 & 15 & 5 & 15 \\
\hline Burkholderia cepacia & 34 & 33 & 19 & 5 & 4 & 4 & 18 & 12 & 23 & 24 & 12 & 20 \\
\hline \multicolumn{13}{|l|}{ Oxidase Negative } \\
\hline Citrobacter freundii & 1 & 1 & 1 & 0 & 0 & 0 & 1 & 1 & 1 & 1 & 0 & 1 \\
\hline Citrobacter youngae & 1 & 1 & 1 & 0 & 0 & 0 & 0 & 1 & 1 & 1 & 0 & 1 \\
\hline Morganella morganii biogp 1 & 1 & 1 & 0 & 0 & 0 & 0 & 1 & 0 & 1 & 1 & 1 & 0 \\
\hline Photorhabdus asymbiotica & 1 & 1 & 1 & 0 & 1 & 0 & 1 & 0 & 1 & 1 & 1 & 1 \\
\hline Pragia fontium & 1 & 1 & 1 & 0 & 0 & 0 & 1 & 0 & 1 & 1 & 1 & 1 \\
\hline Serratia marcescens & 1 & 1 & 0 & 0 & 0 & 0 & 1 & 1 & 0 & 1 & 0 & 1 \\
\hline Proteus vulgaris & 3 & 3 & 0 & 0 & 0 & 1 & 3 & 1 & 2 & 2 & 2 & 2 \\
\hline Photorhabdus luminescens $25 \mathrm{C}$ & 3 & 3 & 2 & 0 & 0 & 0 & 2 & 0 & 2 & 2 & 2 & 1 \\
\hline Proteus mirabilis & 9 & 8 & 3 & 0 & 2 & 1 & 6 & 2 & 6 & 8 & 4 & 6 \\
\hline Pantoea agglomerans complex & 11 & 10 & 4 & 3 & 2 & 4 & 7 & 2 & 4 & 8 & 6 & 8 \\
\hline $\begin{array}{l}\text { TOTAL* } \\
(\%)\end{array}$ & 110 & $\begin{array}{c}104 \\
(94.5)\end{array}$ & $\begin{array}{c}55 \\
(50.0)\end{array}$ & $\begin{array}{c}15 \\
(13.6)\end{array}$ & $\begin{array}{c}12 \\
(10.9)\end{array}$ & $\begin{array}{c}17 \\
(15.5)\end{array}$ & $\begin{array}{c}64 \\
(55.1)\end{array}$ & $\begin{array}{c}35 \\
(31.8)\end{array}$ & $\begin{array}{c}66 \\
(60.0)\end{array}$ & $\begin{array}{c}82 \\
(74.5)\end{array}$ & $\begin{array}{c}42 \\
(38.1)\end{array}$ & $\begin{array}{c}73 \\
(66.3)\end{array}$ \\
\hline
\end{tabular}

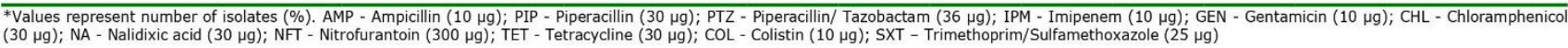

Table 3: Antibiotic resistance profile of the enzyme producing Gram-negative isolates from HIV seropositive patients

\begin{tabular}{|c|c|c|c|c|c|c|c|c|c|c|c|c|}
\hline \multirow[t]{2}{*}{ Isolate Identity } & \multirow{2}{*}{$\begin{array}{c}\text { No of } \\
\text { producers }\end{array}$} & \multicolumn{11}{|c|}{ Resistance profile (number of isolates) } \\
\hline & & AMP & PIP & PTZ & IPM & GEN & $\mathrm{CHL}$ & NA & NFT & TET & $\mathrm{COL}$ & SXT \\
\hline \multicolumn{13}{|l|}{$\underline{\text { Oxidase Positive }}$} \\
\hline Pseudomonas fluorescens 25 & 4 & 3 & 3 & 2 & 0 & 0 & 1 & 2 & 3 & 2 & 0 & 2 \\
\hline Burkholderia pseudomallei & 12 & 12 & 4 & 0 & 1 & 2 & 6 & 2 & 4 & 9 & 5 & 9 \\
\hline Aeromonas hydrophila & 14 & 13 & 9 & 1 & 2 & 3 & 9 & 4 & 7 & 10 & 4 & 11 \\
\hline Burkholderia cepacian & 25 & 24 & 15 & 3 & 3 & 4 & 14 & 10 & 15 & 17 & 11 & 16 \\
\hline \multicolumn{13}{|l|}{$\underline{\text { Oxidase Negative }}$} \\
\hline Citrobacter freundii & 1 & 1 & 1 & 0 & 0 & 0 & 1 & 1 & 1 & 1 & 0 & 1 \\
\hline Citrobacter youngae & 1 & 1 & 1 & 0 & 0 & 0 & 0 & 1 & 1 & 1 & 0 & 1 \\
\hline Morganella morganii biogp 1 & 1 & 1 & 0 & 0 & 0 & 0 & 1 & 0 & 1 & 1 & 1 & 0 \\
\hline Photorhabdus asymbiotica & 1 & 1 & 1 & 0 & 1 & 0 & 1 & 0 & 1 & 1 & 1 & 1 \\
\hline Serratia marcescens & 1 & 1 & 0 & 0 & 0 & 0 & 1 & 1 & 0 & 1 & 0 & 1 \\
\hline Photorhabdus luminescens $25 \mathrm{C}$ & 2 & 2 & 2 & 0 & 0 & 0 & 2 & 0 & 1 & 1 & 1 & 1 \\
\hline Proteus mirabilis & 7 & 6 & 2 & 0 & 2 & 1 & 5 & 1 & 4 & 6 & 3 & 5 \\
\hline Pantoea agglomerans complex & 11 & 10 & 4 & 3 & 2 & 4 & 7 & 2 & 4 & 8 & 6 & 8 \\
\hline $\begin{array}{l}\text { TOTAL* } \\
(\%)\end{array}$ & 80 & $\begin{array}{c}75 \\
(93.8)\end{array}$ & $\begin{array}{c}42 \\
(52.5)\end{array}$ & $\begin{array}{c}09 \\
(11.3)\end{array}$ & $\begin{array}{c}11 \\
(13.8)\end{array}$ & $\begin{array}{c}14 \\
(17.5)\end{array}$ & $\begin{array}{c}48 \\
(60.0)\end{array}$ & $\begin{array}{c}24 \\
(30.0)\end{array}$ & $\begin{array}{c}42 \\
(52.5)\end{array}$ & $\begin{array}{c}58 \\
(72.5)\end{array}$ & $\begin{array}{c}32 \\
(40.0)\end{array}$ & $\begin{array}{c}56 \\
(70.0)\end{array}$ \\
\hline
\end{tabular}




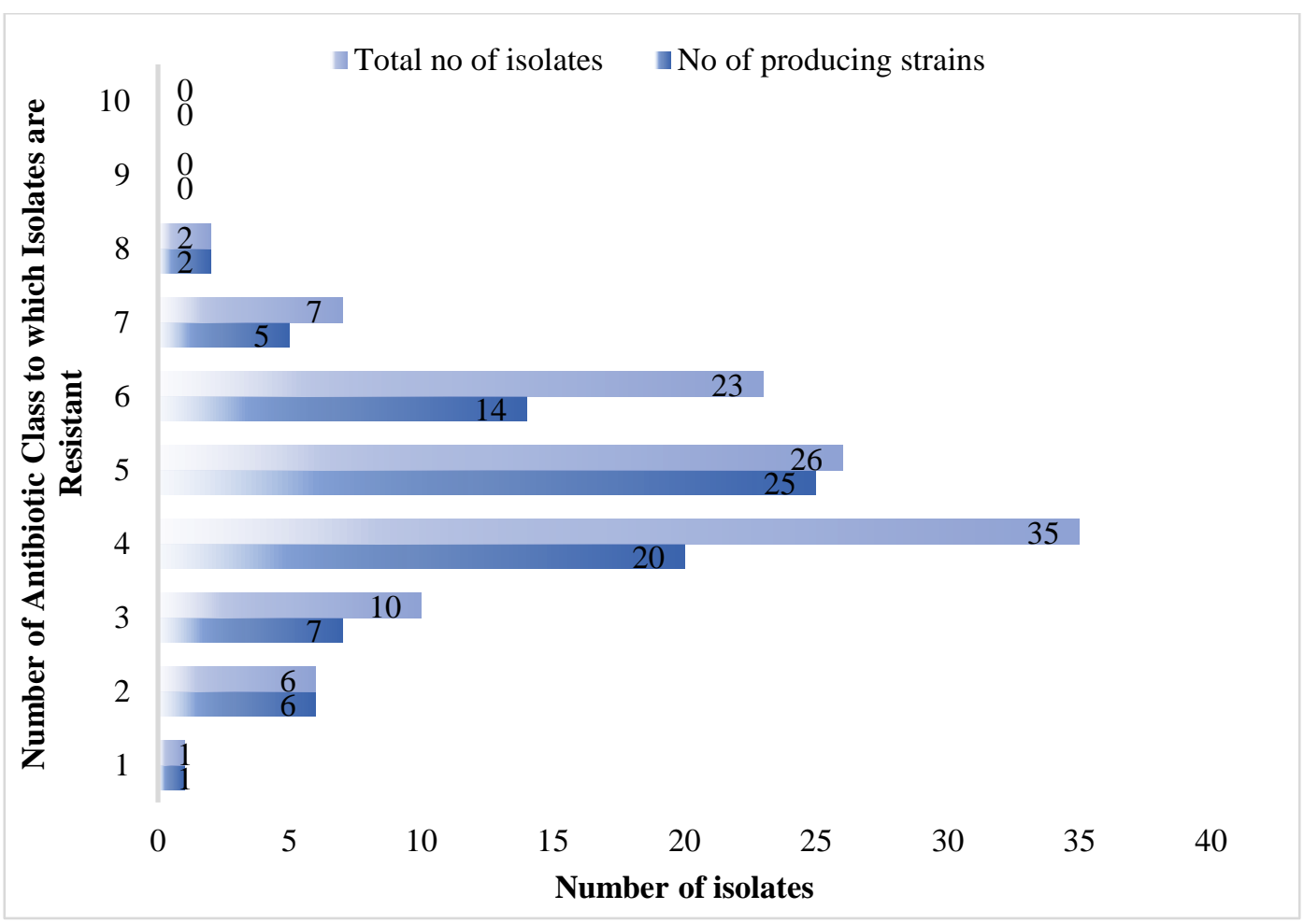

Fig 1: Multiple resistance profile of selected Gram-negative isolates from HIV seropositive patients

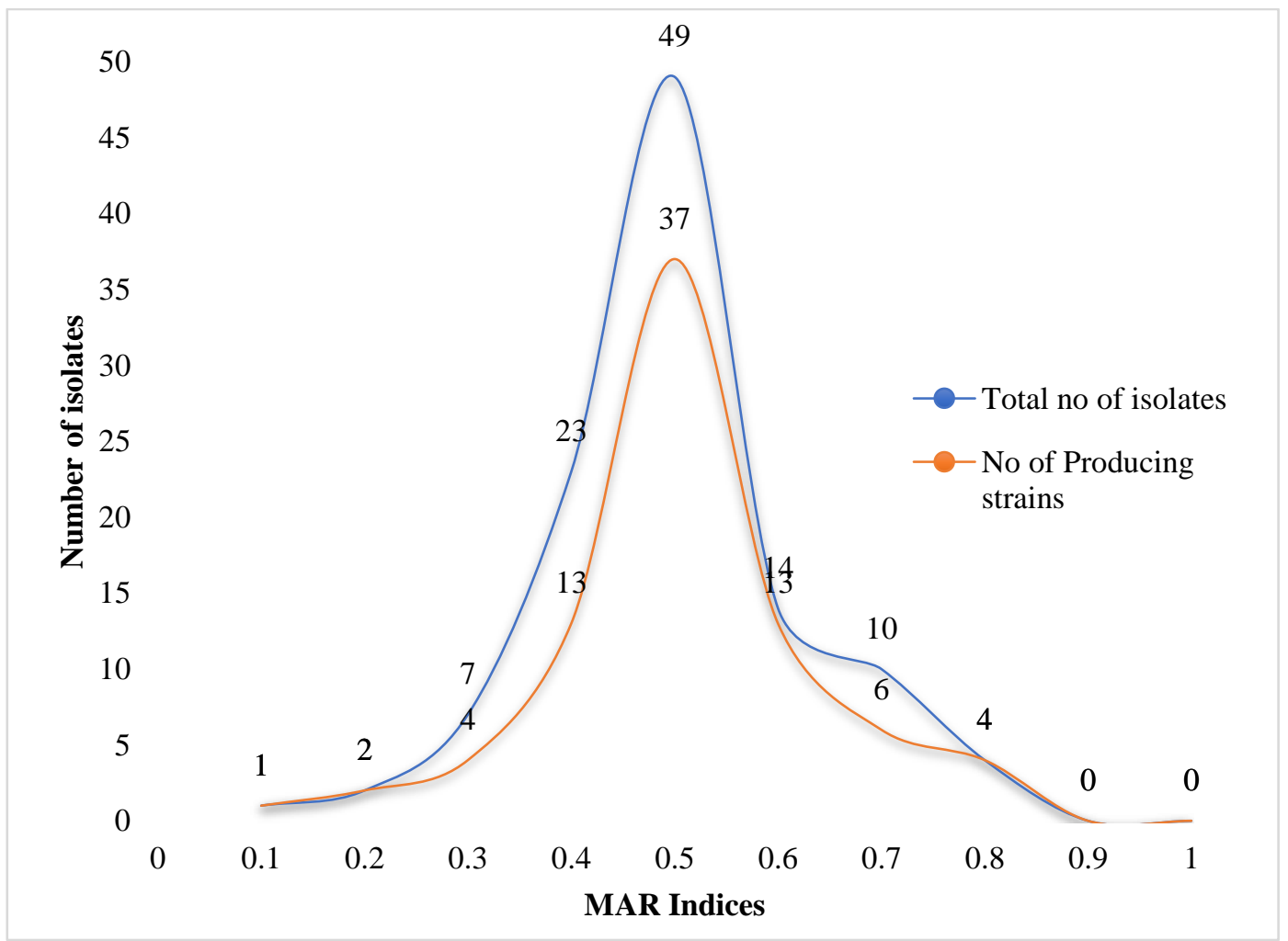

Fig 2: MAR index pattern of selected Gram-negative bacterial isolates from HIV seropositive patients 
while 42 isolates were detected with the doubledisc test (15 Burkholderia cepacia, 8 Pantoea agglomerans complex, 6 Burkholderia pseudomallei, 4 Aeromonas hydrophila, 3 each of Proteus mirabilis and Pseudomonas fluorescens 25, 2 Photorhabdus luminescens 25C and 1 Photorhabdus asymbiotica). However, ESßL production was detected in $12(10.4 \%)$ GNB isolates using both phenotypic methods, and these were 5 Burkholderia cepacia, 3 Pantoea agglomerans complex, 2 Burkholderia pseudomallei, and 1 each of Proteus mirabilis and Pseudomonas fluorescens 25 (Table 4).

\section{Pattern of AmpC $\beta$-lactamase production}

The results of the AmpC $\beta$-lactamase enzyme detection for all the 115 selected GNB isolates revealed that $20.9 \%(24 / 115)$ were positive for AmpC $\beta$-lactamase production; 15 with MHT alone (4 each of Burkholderia cepacia and Pantoea agglomerans complex, 3 Burkholderia pseudomallei, 2 Aeromonas hydrophila and 1 each of Photorhabdus asymbiotica and Proteus mirabilis), 5 with the AmpC EDTA disc test alone (2 Burkholderia cepacia, 1 each of Aeromonas hydrophila, Burkholderia pseudomallei and Citrobacter freundii), and 4 with both tests (2 Pantoea agglomerans complex, 1 Burkholderia cepacia, and 1 Proteus mirabilis) (Table 4).

\section{Pattern of carbapenemase production}

Twelve of the 15 GNB species screened for carbapenemase production had at least one positive isolate in a specie except for Actinobacillus sp., Pragia fontium, and Proteus vulgaris. Altogether, 29 GNB isolates (25.2\%) were positive for carbapenemase production; 4 with the modified Hodge test alone; 23 with the EDTA disc test alone, and 2 isolates with both phenotypic methods (Table 4).

Table 4: Detection of ESßL, AmpC and carbapenemase production in selected Gram-negative isolates from HIV seropositive patients

\begin{tabular}{|c|c|c|c|c|c|c|c|c|c|c|c|c|c|}
\hline \multirow[t]{2}{*}{ Isolate identity } & \multirow{2}{*}{$\begin{array}{l}\text { Number } \\
\text { of isolates } \\
\text { tested }\end{array}$} & \multicolumn{4}{|c|}{$E s \beta L$} & \multicolumn{4}{|c|}{ AmpC } & \multicolumn{4}{|c|}{ Carbapenemase } \\
\hline & & $\mathrm{CDT}$ & DDT & $\begin{array}{l}\text { CDT/ } \\
\text { DDT }^{\mathrm{a}}\end{array}$ & $\begin{array}{l}\text { Total } \\
\text { Positive }\end{array}$ & MHT & EDTA & $\begin{array}{l}\text { MHT/ } \\
\text { EDTA }^{b}\end{array}$ & $\begin{array}{l}\text { Total } \\
\text { Positive }\end{array}$ & MHT & EDTA & $\begin{array}{l}\text { MHT/ } \\
\text { EDTA }\end{array}$ & $\begin{array}{l}\text { Total } \\
\text { Positive }\end{array}$ \\
\hline \multicolumn{14}{|l|}{ Oxidase Positive } \\
\hline Actinobacillus sp. & 2 & 0 & 0 & 0 & 0 & 0 & 0 & 0 & 0 & 0 & 0 & 0 & 0 \\
\hline Pseudomonas fluorescens 25 & 6 & 0 & 2 & 1 & 3 & 0 & 0 & 0 & 0 & 0 & 2 & 0 & 2 \\
\hline Burkholderia pseudomallei & 17 & 3 & 4 & 2 & 9 & 3 & 1 & 0 & 4 & 0 & 4 & 0 & 4 \\
\hline Aeromonas hydrophila & 21 & 7 & 4 & 0 & 11 & 2 & 1 & 0 & 3 & 1 & 3 & 0 & 4 \\
\hline Burkholderia cepacian & 34 & 5 & 10 & 5 & 20 & 4 & 2 & 1 & 7 & 0 & 7 & 0 & 7 \\
\hline \multicolumn{14}{|l|}{ Oxidase Negative } \\
\hline Citrobacter freundii & 1 & 0 & 0 & 0 & 0 & 0 & 1 & 0 & 1 & 0 & 1 & 0 & 1 \\
\hline Citrobacter youngae & 1 & 0 & 0 & 0 & 0 & 0 & 0 & 0 & 0 & 0 & 1 & 0 & 1 \\
\hline Morganella morganii biogp 1 & 1 & 0 & 0 & 0 & 0 & 0 & 0 & 0 & 0 & 0 & 1 & 0 & 1 \\
\hline Photorhabdus asymbiotica & 1 & 0 & 1 & 0 & 1 & 1 & 0 & 0 & 1 & 1 & 0 & 0 & 1 \\
\hline Pragia fontium & 1 & 0 & 0 & 0 & 0 & 0 & 0 & 0 & 0 & 0 & 0 & 0 & 0 \\
\hline Serratia marcescens & 1 & 1 & 0 & 0 & 1 & 0 & 0 & 0 & 0 & 0 & 1 & 0 & 1 \\
\hline Proteus vulgaris & 3 & 0 & 0 & 0 & 0 & 0 & 0 & 0 & 0 & 0 & 0 & 0 & 0 \\
\hline Photorhabdus luminescens $25 \mathrm{C}$ & 3 & 0 & 2 & 0 & 2 & 0 & 0 & 0 & 0 & 1 & 0 & 0 & 1 \\
\hline Proteus mirabilis & 10 & 2 & 2 & 1 & 5 & 1 & 0 & 1 & 2 & 1 & 1 & 1 & 3 \\
\hline Pantoea agglomerans complex & 13 & 2 & 5 & 3 & 10 & 4 & 0 & 2 & 6 & 0 & 2 & 1 & 3 \\
\hline TOTAL & 115 & 20 & 30 & 12 & 62 & 15 & 5 & 4 & 24 & 4 & 23 & 2 & 29 \\
\hline
\end{tabular}




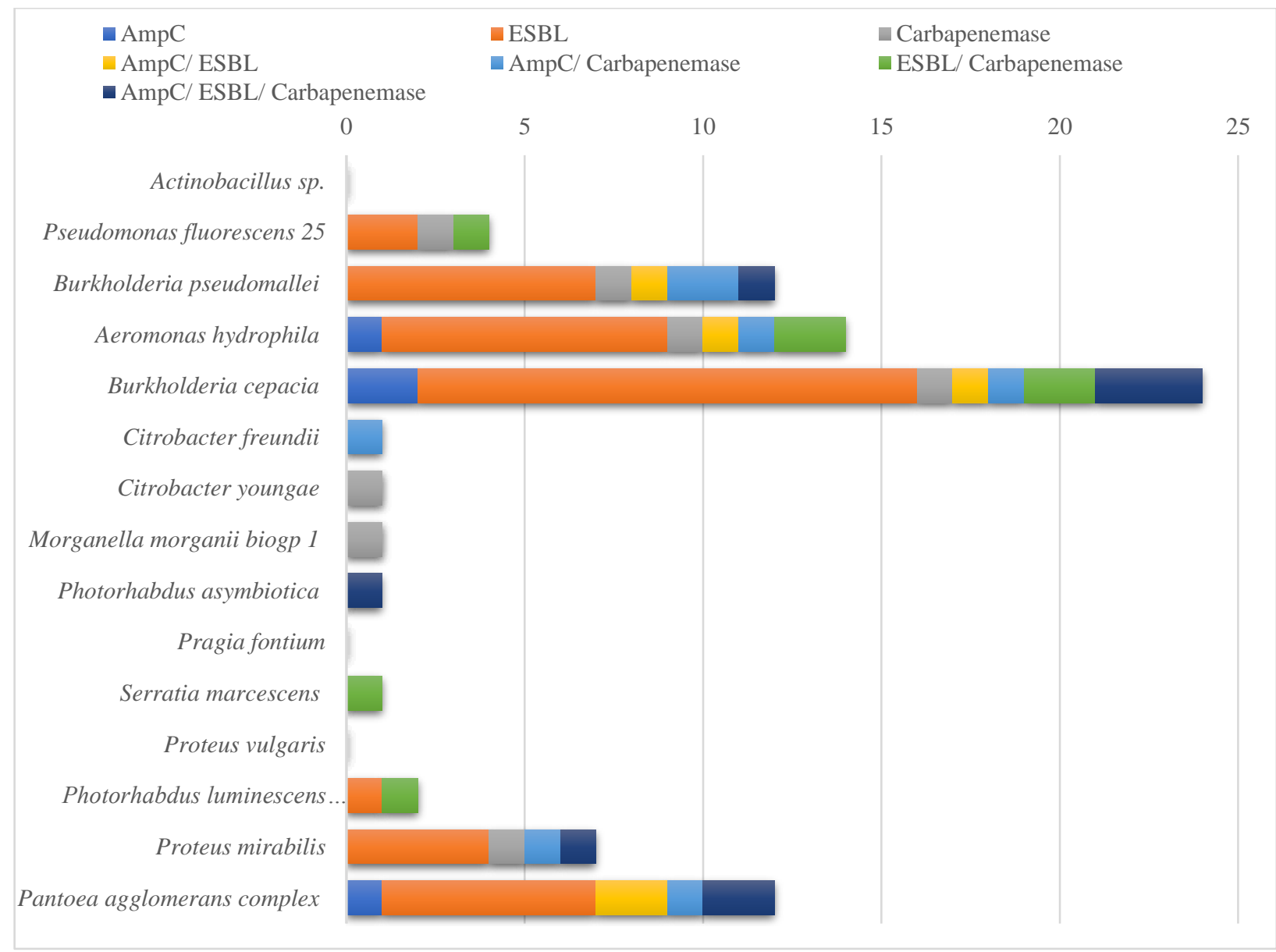

Fig 3: Co-production profile for selected Gram-negative bacteria isolates from HIV seropositive patients

\section{Co-production of ESBL, AmpC, and carbapenem- mase:}

The presence of either Es $\beta L$, AmpC, or carbapenemase or the co-production of two or all three enzymes was evaluated in a total of 80 isolates. Only $8(10.0 \%)$ isolates produced all three enzymes and these include 3 Burkholderia cepacia, 2 Pantoea agglomerans complex, and 1 each of Burkholderia pseudomallei, Photorhabdus asymbiotica and Proteus mirabilis. The co-production of two enzymes (either Es $\beta$ L/

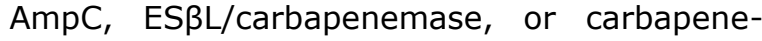
mase/AmpC) was detected in 19 (23.8\%) GNB isolates while the last $53(66.2 \%)$ GNB isolates produced only 1 enzyme each (Table 4 and Fig 3).

Resistance pattern to beta-lactam antibiotics and production of Es $\beta \mathrm{L}, \mathrm{AmpC}$, and carbapenemmase among GNB isolates

In all 12 isolates resistant to imipenem, 11 (10 of which were MDR) produced either $\mathrm{ES} \beta \mathrm{L}, \mathrm{AmpC}$, carbapenemase, or co-produced two or all three enzymes. The last resistant isolate (Burkholderia cepacia) albeit MDR, did not produce any of the enzymes screened for. Four of them produced 2 enzymes each (carbapenemase and AmpC, 2; AmpC and ESßL, 2) while 5 produced only one enzyme each (ES $\beta L$, 4; carbapenemase, 1). Only 2 of them (Burkholderia cepacia, 1; Photorhabdus asymbiotica, 1) produced all the three enzymes.

Seventy-five of the enzyme producers were resistant to ampicillin, 8 of them produced all three enzymes (all MDR), 48 produced only one of the three $(E S \beta L, 38$; AmpC, 4; carbapenemase, 6) while the remaining 19 isolates produced two out of the three enzymes (carbapenemase and AmpC, 7; AmpC and ES $\beta$, 4; and carbapenemase and ESßL, 8) (Table 3). Fifty-five of the isolates were resistant to piperacillin, 13 of them (all MDR) were negative for the three enzymes; 3 produced all the three enzymes; co-production of two enzymes was detected in 9 isolates (carbapenemase and AmpC, 4; AmpC and ESBL, 2; and carbapenemase and $E S \beta L, 4)$ while the remaining 30 isolates produced only one enzyme each (ESBL, 23; AmpC, 2; carbapenemase, 5). Six out of 
fifteen isolates resistant to piperacillin/tazobactam did not produce any of the enzymes, while none produced all three. Four co-produced two enzymes (carbapenemase and AmpC, 1; AmpC and ESßL, 1; carbapenemase and ES $\beta L$, 2) and 5 isolates produced one enzyme each (ESßL, 4; carbapenemase, 1).

\section{Discussion:}

The rising prevalence of multiple resistance to previously effective antibiotics in GNB as a result of the production of enzymes that confer resistance to drugs has been a worrisome trend in the antibiotic treatment regimen for clinicians. This study was designed to phenotypically screen for the production of ES $\beta L s, A m p C \beta$-lactamase, and carbapenemase in selected GNB isolates cultured from HIV seropositive patients in southwestern Nigeria. We report a high level of resistance of the GNB to ampicillin (94.5\%), a commonly prescribed beta-lactam antibiotic. This resistance is likely the result of beta-lactam hydrolysing enzymes as observed in this study. On the other hand, $10.9 \%$ of the GNB were resistant to imipenem. This rate is lower than that reported by Dumaru et al., (58) where imipenem resistance rates for different species ranged between $0 \%$ to $60 \%$. Again, Jalalvand et al., (21) reported resistance rates of $90 \%$ and $96.4 \%$ to imipenem and meropenem respectively.

However, resistance rate to piperacillin/ tazobactam and imipenem was $11.3 \%$ and $13.8 \%$ respectively for the enzyme-producing GNB isolates. Yet, imipenem was the most active of all the antibiotics tested against the selected bacterial isolates. This high activity is in line with a previous study carried out by Ogbolu et al., (44) where imipenem was also the most effective of all the drugs tested. This highlights the fact that despite the rising prevalence of resistance to imipenem reported globally (59-62), it is still probably a highly effective antimicrobial agent in the event of therapeutic failure of other commonly prescribed antimicrobials particularly in this environment where carbapenems have been reported as the established treatment choice for serious infections caused by ES $\beta$ L producing GNB (63).

The proportion of MDR strains among the selected GNB isolates was high (93.6\% of the isolates were MDR), and for the hydrolysing enzyme-producing strains, $91.3 \%$ were MDR. The high values of MAR indices for ES $\beta L, A m p C$, and carbapenemase-producing strains (98.8\% with MAR $\geq 0.2$ ) implies that these isolates were obtained from an antibiotic pressurised environment. This is most likely because the isolates were recovered from HIV-infected patients who are immunocompromised and are probably in constant contact with the hospital environment.

A high rate of ES $\beta L$ production (53.9\%, $62 / 115)$ was detected among the isolates in the study. The presence of ES $\beta$ L trait in MDR GNB, particularly from clinical samples may be significant because it could be an indication of colonisation, with high potential for transfer from one patient to another (65). Colonisation by ES $\beta$ L producing GNB has been linked to prior exposure to antibiotics and hospitalisation (65) which predisposes the host to infections caused by these organisms (31).

The frequency of AmpC $\beta$ lactamase and carbapenemase producers were not as high as that of ESßL, with only $24(20.9 \%)$ and 29 $(25.2 \%)$ respectively. However, the rate of ES $\beta L$ and AmpC production in this study is much higher than previously reported rates in Nigeria; 9.3\% ES $\beta$ L rate in 2007 (66), 15.8\% ES $\beta L$ and $11.3 \%$ AmpC rates from northern Nigeria (7), and $15.8 \% \mathrm{ES} \beta \mathrm{L}$ and $9.6 \% \mathrm{AmpC}$ rates in southern Nigeria (44). Our rates however agree with the report of Iroha et al., (42) and Yusuf et al., (46) both in Nigeria where the prevalence rate of ES $\beta$ L production was $56.6 \%$ and $58.0 \%$ respectively. Very recently, Ugah and Udeani (67) reported $E S \beta L$ production rate of $61.5 \%$ in Enterobacteriaceae isolates from south-eastern Nigeria. A study conducted in Iran (21) reported that $73.3 \%$ of carbapenem-resistant isolates were carbapenemase-producing ones. This high rate of production in our isolates could also be due to the immunocompromised nature of the patients. However, no ESßL production was detected in the two Citrobacter species, Morganella morganii biogp 1, and Proteus vulgaris; and no AmpC production was detected in Citrobacter youngae, Morganella morganii biogp 1, Photorhabdus luminescens 25C, Pseudomonas fluorescens 25 and Serratia marcescens.

Carbapenems have been reported to be the cornerstone of therapy for patients who have serious infections in which ES $\beta L$ producers are implicated $(63,68)$. The production of carbapenemases by some of the isolates although not remarkably high is quite worrisome because of the potential threat to the treatment regimen in the group of patients from which they were recovered. The production of ES $\beta$ Ls is a significant factor in the development of resistance of pathogenic GNB to broad-spectrum antibiotics, and the co-production of any of the three enzymes screened in this study portends serious implications especially for debilitated and immunosuppressed individuals such as HIVinfected patients. It also poses serious challenges for the treatment of opportunistic infections which is quite common in this group 
of patients due to their immuno-compromised state.

In this study, there was co-production of two or more of the enzymes among the isolates. The highest number of strains that produced at least one of the enzymes was Pantoea agglomerans, formerly called, and identified by the Microbact 24E identification kit as Enterobacter agglomerans, $92.3 \%$ of the strains of this bacterium tested was a producer of at least one of the enzymes screened for and 2 of 13 strains tested produced all three enzymes. Pantoea agglomerans has been reported to be an opportunistic pathogen, especially in the immunosuppressed persons such as neonates, premature infants, burns or multiply traumatised patients, and patients with leukaemia or those undergoing immunosuppressive therapy, and not excluding HIV-infected individuals. It has been known to cause a range of infections, including wound, blood stream, and urinary tract infections. Infections are typically acquired from infected vegetation penetrating the skin, or hospital-acquired when associated with the use of contaminated intravenous products due to its ability to grow in commercial infusion fluids (69) or exposure of hospitalised, often immunocompromised individuals to medical equipment or fluids contaminated with this bacterium (70). Bloodstream infection can lead to disseminated disease, mainly septic arthritis, but also endophthalmitis, periostitis, endocarditis and osteomyelitis in humans (70).

Also worthy of note are the species, Burkholderia cepacia (formerly Pseudomonas cepacia) and Burkholderia pseudomallei (formerly Pseudomonas pseudomallei) (71) in which $70.6 \%$ of each was capable of producing at least one of the enzymes (24/34 and 12/17 respectively). B. cepacia has been implicated in lung infections in patients with chronic granulomatous disease usually associated with pneumonia and septicaemia which are often associated with high fatality (72-75), although they rarely cause infection in the immunocompetent host. $B$. cepacia is known to be resistant to most antimicrobial agents and can acquire resistance against many more. As such, effective therapies are not clear-cut; decisions on the treatment of $B$. cepacia infections are made on a case-by-case basis, and prevention of infection is, therefore, the focus at management (76-78). Burkholderia pseudomallei, on the other hand, is a highly pathogenic organism that is known to cause an infection called melioidosis, a potentially life-threatening infectious disease affecting mammals, including humans (79). The organism is intrinsically resistant to a wide range of antimicrobials (80), and treatment with ineffective antimicrobials may result in treatment failure leading to case fatality rates that may exceed $70 \%$ (81). Infections are often profoundly serious as clinical presentations may vary, and can culminate into diseases of the kidney, blood, heart, and other fatal disorders.

Proteus mirabilis is known to cause $90 \%$ of all Proteus infections in humans. It is thought that the majority of $P$. mirabilis urinary tract infections (UTI) are retrograde, resulting from the ascension of bacteria from the lower genitourinary tract, while others are by direct contact with infected persons, particularly in healthcare settings (82). Proteus species can also cause infection in the respiratory tract, eye, ear, nose, skin, throat, as well as in burns and wounds, mostly in hospitalised patients (82). Photorhabdus asymbiotica has been reported to be infectious to humans, although infections are mostly non-fatal (83). It is pertinent to note that the most prevalent GNB isolates recovered in our study were opportunistic pathogens that generally occur as contaminants on environmental surfaces within the healthcare setting. This could probably be adduced to the fact that the population from which the isolates were recovered were immunosuppressed by HIV infection, and as such are prone to colonisation by these non-virulent organisms. Again, these patients pay regular visits to the hospital for clinic visitations, monitoring of their health and immune status, and for treatments when ill or experiencing symptoms associated with AIDSrelated complexes.

The rapid detection of ESBLs in MDR organisms is highly essential to establish appropriate antibiotic treatment, as well as implement infection control measures. The KPCs, and OXA48 , are among the most prevalent carbapenemases worldwide (84) and have been reported to cause outbreaks. NDM-1 can spread widely, as the plasmids that carry the NDM-1 gene are of broad host range, implying that they can disseminate easily between other members of the Enterobacteriaceae and unrelated species (85). The horizontal transfer of the NDM-1 gene itself between different plasmids in the same organism has been documented (86).

A major limitation of our study was the inability to confirm the genes encoding ESßL, AmpC, and carbapenemase in our isolates with a molecular method which is the 'gold standard' for detecting the presence of genes responsible for the expression of these enzymes. This is particularly concerning as previous reports have shown that organisms sensitive to carbapenems in the phenotypic test sometimes harbour carbapenemase gene detected by polymerase chain reaction. Infections associated with such 
wrongly characterized isolates have resulted in treatment failures due to limited antibiotic options, sporadic outbreaks of infections caused by these organisms, extended hospital stays and ultimately higher cost of treatment, as well as increased morbidity and mortality. The use of combination therapy with two active drugs, colistin/tigecycline with intravenous fosfomycin, has been recommended for the treatment of infection caused by these organisms (87), but more recently, fosfomycin, aminoglycosides, and temocillin were reported to be relatively effective, and may well substitute carbapenems for therapy in the treatment of ES $\beta L$ producing Enterobacteriaceae (63).

In conclusion, this study reports high rate of ESBL, AmpC, and carbapenemase coproduction in selected GNB pathogen. The EDTA method was more sensitive in detecting carbapenemase production while MHT was better at detecting AmpC enzyme. A high proportion of the enzyme producing GNB were MDR and had high MAR indices $(98.8 \%$ with $M A R \geq 0.2)$, implying that the isolates had been exposed to a myriad of antibiotics. As such, routine checks for antibiotic hydrolysing enzyme production among bacterial isolates in clinical laboratories by phenotypic or genotypic methods should be embraced. Continuous surveillance, monitoring, screening, and reporting of isolates capable of producing these enzymes is essential to curtail the scourge of antibiotic resistance, as well as to understand better the mechanisms behind these traits.

\section{References:}

1. Collignon, P., Aarestrup, F. M., Irwin, R., et al. Human deaths and third-generation cephalosporin use in Poultry, Europe. Emerg Infect Dis. 2013; 19: 13391340. DOI: 10.3201/eid1908.120681.

2. Chantziaras, I., Boyen, F., Callens, B., et al. Correlation between veterinary antimicrobial use and antimicrobial resistance in food-producing animals: a report on seven countries. J Antimicrob Chemother. 2014; 69: 827-834. DOI: $10.1093 / \mathrm{jac} / \mathrm{dkt} 443$.

3. Livermore, D. M. The need for new antibiotics. Clin Microbiol Infect. 2004; 10 (Suppl 4): 1-9.

4. de Lencastre, H., Oliveira, D., and Tomasz, A. Antibioticresistant Staphylococcus aureus: a paradigm of adaptive power. Curr Opin Microbiol. 2007; 10: 428-435.

5. Paterson, D. L. Resistance in gram-negative bacteria: Enterobacteriaceae. Am J Med. 2006; 119 (6 Suppl 1): S20-8; discussion S62-S70.

6. Nordmann, P., Dortet, L., and Poirel, L. Rapid detection of extended-spectrum $\beta$-lactamase-producing Enterobacteriaceae. J Clin Microbiol. 2012; 50: 3016-3022.

7. Yusuf, I., and Haruna, M. Detection of AmpC and ES $\beta \mathrm{L}$ Producers among Enterobacteriaceae in a Tertiary Health Care in, Kano- Nigeria. Int J Sci Tech. 2013; 3 (4): 220 $-225$.

8. Ghafourian, S., Sadeghifard, N., Soheili, S., et al. Extended-spectrum beta-lactamases: definition, classification, and epidemiology. Curr Issues Mol Biol. 2015; $17: 11-21$.
9. Ruppé, É., Woerther, P. L., and Barbier, F. Mechanisms of antimicrobial resistance in gram-negative bacilli. Ann Intensive Care. 2015; 5 (1): 1

10. Thenmozhi, S., Moorthy, K., Sureshkumar, B., et al. Antibiotic resistance mechanism of $E S B L$ producing Enterobacteriaceae in clinical field: a review. Int J Pure Appl Biosci. 2014; 2 (3): 207-226.

11. Taneja, N., and Sharma, M. ES $\beta$ Ls detection in clinical microbiology: why \& how? Indian J Med Res. 2008; 127: 297-300.

12. Adamski, C. J., Cardenas, A. M., Brown, N. G., et al. Molecular basis for the catalytic specificity of the CTX-M extended-spectrum $\beta$-lactamases. Biochem. 2014; 54 (2): 447-457.

13. Leylabadlo, H. E., Pourlak, T., Bialvaei, A. Z., et al. Extended-spectrum beta-lactamase-producing gramnegative bacteria in Iran: A review. Afr J Infect Dis. 2017; 11 (2): 39-53. doi.org/10.21010/ajid.v11i2.6

14. Zeynudin, A., Pritsch, M., Schubert, S., et al. Prevalence and antibiotic susceptibility pattern of CTX-M type extended-spectrum $\beta$-lactamases among clinical isolates of gram-negative bacilli in Jimma, Ethiopia. BMC Infect Dis. 2018; 18: 524. Doi.org/10.1186/s12879-018-34367.

15. van Hoek, A. H., Schouls, L., van Santen, M. G., et al. Molecular characteristics of extended-spectrum cephalosporin-resistant Enterobacteriaceae from humans in the community. PLoS One. 2015; 10: e0129085.

16. Jacoby, G. A. AmpC beta-lactamases. Clin Microbiol Rev. 2009; 22: 161-182

17. Lan, N. P. H., Hien, N. H., Phuong, T. L. T., et al. Phenotypic and genotypic characteristics of ESBL and AmpC producing organisms associated with bacteraemia in Ho Chi Minh City, Vietnam. Antimicrob Resist Infect Control. 2017; 6: 105. DOI 10.1186/s13756-017-0265-1

18. Reuland, E. A., Halaby, T., Hays, J. P., et al. Plasmidmediated AmpC: Prevalence in community-acquired isolates in Amsterdam, the Netherlands, and risk factors for carriage. PLoS One. 2015; 10 (1): 1-9.

19. Eser, O. K., Altun Uludağ, H., Ergin, A., et al. Carbapenem resistance in ESBL positive Enterobacteriaceae isolates causing invasive infections. Mikrobiyol Bul. 2014; 48: 59-69.

20. Gijón, D., Curiao, T., Baquero, F., et al. Fecal carriage of carbapenemase-producing Enterobacteriaceae: a hidden reservoir in hospitalised and non-hospitalised patients. J Clin Microbiol. 2012; 50: 1558-1563.

21. Jalalvand, K., Shayanfar, N., Shahcheraghi, F., et al. Evaluation of Phenotypic and Genotypic Characteristics of Carbapenemases-producing Enterobacteriaceae and Its Prevalence in a Referral Hospital in Tehran City. Iran J Pathol. 2020; 15 (2): 86-95. DOI: $10.30699 /$ ijp.2020.111181.2188

22. Queenan, A. M., and Bush, K. Carbapenemases: the Versatile $\beta$-Lactamases. Clin Microbiol Rev. 2007; 20 (3): 440-458.

23. Potron, A., Poirel, L., Bussy, F., et al. Occurrence of the carbapenem hydrolysing b-lactamase gene blaOXA-48 in the environment in Morocco. Antimicrob Agents Chemother. 2011; 55: 5413.

24. Overdevest, I. T. M. A., Willemsen, I., Elberts, S., et al. Laboratory Detection of Extended-Spectrum-BetaLactamase-Producing Enterobacteriaceae: Evaluation of Two Screening Agar Plates and Two Confirmation Techniques. J Clin Microbiol. 2011; 49 (2): 519-522.

25. Azimi, L., Nordmann, P., Lari, A. R., et al. First report of OXA-48-producing Klebsiella pneumoniae strains in Iran. GMS Hyg Infect Control. 2014; 9(1): Doc07.

26. Mohd Khari, F. I., Karunakaran, R., Rosli, R., et al. Genotypic and Phenotypic Detection of AmpC $\beta$ lactamases in Enterobacter spp. Isolated from a Teaching Hospital in Malaysia. PLoS One. 2016; 11(3): e0150643. doi.org/10.1371/journal.pone.0150643

27. Ruh, E., Zakka, J., Hoti, K., et al. Extended-spectrum $\beta$ lactamase, plasmid-mediated AmpC $\beta$-lactamase, fluoro- 
quinolone resistance, and decreased susceptibility to carbapenems in Enterobacteriaceae: fecal carriage rates and associated risk factors in the community of Northern Cyprus. Antimicrob Resist Infect Contr. 2019; 8: 98. doi.org/10.1186/s13756-019-0548-9

28. Schwaber, M. J., and Carmeli, Y. Mortality and delay in effective therapy associated with extended-spectrum $\beta$ lactamase production in Enterobacteriaceae bacteraemia: a systemic review and meta-analysis. J Antimicrob Chemother. 2007; 60: 913-920.

29. Roberts R. R., Hota, B., Ahmad, I., et al. 2009. Hospital and societal costs of antimicrobial-resistant infections in a Chicago teaching hospital: implications for antibiotic stewardship. Clin Infect Dis. 2009; 49(8): 1175-1184. doi: $10.1086 / 605630$.

30. Dautzenberg, M. J. D., Wekesa, A. N., Gniadkowski, M. et al. The Association Between Colonization with Carbapenemase-Producing Enterobacteriaceae and Overall ICU Mortality. Crit Care Med. 2015; 43 (6): 11701177. DOI: $10.1097 / C C M .0000000000001028$

31. Pana, Z. D., and Zaoutis, T. Treatment of extendedspectrum $\beta$-lactamase-producing Enterobacteriaceae (ESBLs) infections: what have we learned until now? F1000Res. 2018; 7: F1000 Faculty Rev-1347. DOI: $10.12688 /$ f1000research.14822.1

32. Fatemeh, A., Emran, A., Elnaz, K., et al. The frequency of extended-spectrum beta-lactamase (ESßL) in Escherichia coli and Klebsiella pneumoniae: a report from Mashhad. Iran J Med Bacteriol. 2012; 1 (3): 12-19.

33. Abhijit, A., Sunita, N., and Maria, K. Study of urinary isolates with reference to extended-spectrum betalactamases detection and antibiogram. J Evol Med Dent Sci. 2013; 2 (9): 1049-1055.

34. Kritu, P., Prakash, G., Shiba, K. R., et al. Antibiogram typing of gram-negative isolates in different clinica samples of a tertiary hospital. Asian J Pharm Clin Res. 2013; 6 (1): 153-156.

35. Majda, Q., Najma, A., and Summyia, B. Evaluation of extended-spectrum beta-lactamase mediated resistance in Escherichia coli and Klebsiella in urinary tract infection at a tertiary care hospital. Biomedica. 2013; 29:78-81.

36. Meeta, S., Sati, P., and Preeti, S. Prevalence and antibiogram of extended-spectrum $\beta$-lactamase (ES $\beta L$ ) producing gram-negative bacilli and further molecular characterisation of ES $\beta$ L producing Escherichia coli and Klebsiella spp. J Clin Diag Res. 2013; 7 (10): 2168-2172.

37. Paterson, D. A., and Bonomo, R. A. Extended-spectrum b-lactamases: a clinical update. Clin Microbiol Rev. 2005; 18: 657-686.

38. Sibhghatulla, S., Jamale, F., Shazi, S. et al. Prevalence of multidrug-resistant and extended-spectrum betalactamase-producing Pseudomonas aeruginosa in a tertiary care hospital. Saudi J Bio Sc. $2014 ; 22$ (1): 6264.

39. Aibinu, I., Odugbemi, P., and Brian, J. M. Extendedspectrum $\beta$-lactamase in isolates of Klebsiella spp and Escherichia coli from Lagos. Nig J HIth Biomed Sci. 2003; 2: 53-60.

40. Soge, O. O., Queenan, A. M., Ojo, K. K., et al. CTX-M-15 extended-spectrum $\beta$-lactamase from Nigeria Klebsiella Pneumoniae. J Antimicrob Chemother. 2005; 57 (1): 2430. doi: $10.1093 / \mathrm{jac} / \mathrm{dki} 429$.

41. Soge, O. O., Adeniyi, B. A., and Roberts, M. C. New antibiotic resistance genes associated with CTX-M plasmids from uropathogenic Nigeria Klebsiella pneumoniae. J Antimicrob Chemother. 2006; 58 (5): 1048-1053. doi: 10.1093/jac/dkl370

42. Iroha, I. R., Amadi, E. S., Oji, A. E., et al. Detection of Plasmid Borne Extended-Spectrum Beta-Lactamase Enzymes from Blood and Urine Isolates of GramNegative Bacteria from a University Teaching Hospital in Nigeria. Curr Res Bacteriol. 2010; 3: 77-83.

43. Afunwa, R. A., Odimegwu, D. C., Iroha, I. R., et al. Antimicrobial resistance status and prevalence rates of extended-spectrum beta-lactamase (ES $\beta L$ ) producers isolated from a mixed human population. Bosn J Basic Med Sci. 2011; 11(2): 91-6.

44. Ogbolu, D. O., Terry-Alli O.A., Olanipekun L.B., et al. Faecal carriage of extended-spectrum beta-lactamase (ESßL)-producing commensal Klebsiella pneumoniae and Escherichia coli from hospital out-patients in Southern Nigeria. Int J Med Med Sci. 2013; 5 (3): 97-105.

45. Yusuf, I., Haruna, M., and Yahaya, H. Prevalence and antibiotic susceptibility of AmpC and ES $\mathrm{AL}$ producing clinical isolates at a tertiary health care center in Kano, Northwest Nigeria. Afr J Clin Exper Microbiol. 2013; 14(2): 109-119.

46. Yusuf, I., Yahaya, S., Qabli S., et al. Phenotypic Detection of Extended Spectrum Beta-lactamase and Carbapenemase Co-producing Clinical Isolates from Two Tertiary Hospitals in Kano, northwest Nigeria. Ethiop J Health Sci. $2017 ; 27$ (1): 3-10. DOI: dx.doi.org/10.4314/ejhs.v27i1.2

47. Olowe, O. A., and Aboderin, B. W. Detection of ExtendedSpectrum $\beta$-Lactamase Producing Strains of (Escherichia coli) and (Klebsiella sp.) in a Tertiary Health Centre in Ogun State. Int J Trop Med. 2010; 5 (3): 62-64.

48. Manenzhe, R. I., Zar, H. J., Nicol, M. P., et al. The spread of carbapenemase-producing bacteria in Africa: a systematic review. J Antimicrob Chemother. 2014; 70: 23-40.

49. Le Terrier, C., Masseron, A., Uwaezuoke, N. S., et al. Wide spread of carbapenemase-producing bacterial isolates in a Nigerian environment. J Global Antimicrob Res. 2020; 21: 321-323. doi.org/10.1016/j.jgar.2019.10.014

50. Adeyemi, F. M., Ako-Nai, K. A., Adejuyigbe, E. A., et al. Molecular Characterisation and Antibiotic Resistance Profiles of Bacterial Isolates Cultured from HIV Seropositive Patients. Arch Clin Microbiol. 2015; 6 (1:2): $1-11$

51. Ako-Nai, K. A., Adeyemi, F. M., Adejuyigbe, E. A., et al. The Dynamics of Bacteria Population on the skin, throat, and gastrointestinal tracts of HIV-seropositive patients. Ann Trop Med Publ HIth. 2015; 5 (8): 164-176.

52. CLSI. Performance Standards for Antimicrobial Susceptibility Testing. 29th ed. CLSI supplement M100. Wayne, PA: Clinical and Laboratory Standards Institute; 2019.

53. Magiorakos, A. P., Srinivasan, A., Carey, R. B., et al. Multidrug-resistant, extensively drug-resistant, and pan drug-resistant bacteria: an international expert proposal for interim standard definitions for acquired resistance. Clin Microbiol Infect. 2012; 18 (3): 268 - 281.

54. Krumperman, P. H. Multiple antibiotics resistance indexing of $E$. coli to identify high risks sources of faecal contamination of foods. Appl Env Microbiol. 1983; 46: 165-170.

55. Jarlier, V., Nicholas, M.-H., Fournier, G., et al. Extended broad-spectrum b-lactamases conferring transferable resistance to newer b-lactam agents in Enterobacteriaceae: hospital prevalence and susceptibility patterns. Rev Infect Dis. 1988; 10: 867-878.

56. Carter, M. W., Oakton, K. J., Warner M., et al. Detection of extended-spectrum b-lactamases in Klebsiellae with the Oxoid Combination Disk Method. J Clin Microbiol. 2000; 38: 4228-4232.

57. Black, J. A., Moland, E. S., and Thomson, K. S. AmpC disk test for detection of plasmid-mediated AmpC $\beta$ lactamases in Enterobacteriaceae lacking chromosomal AmpC $\beta$-lactamases. J Clin Microbiol. 2005; 43 (7): 3110 - 3113 .

58. Dumaru, R., Baral, R., and Shrestha, L. B. Study of biofilm formation and antibiotic resistance pattern of gram-negative Bacilli among the clinical isolates at BPKIHS, Dharan. BMC Res Notes. 2019; 12: 38. doi.org/10.1186/s13104-019-4084-8.

59. Chakraborty, D., Basu, S., and Das, S. A study on infections caused by Metallo Beta-Lactamase Producing Gram-negative Bacteria in Intensive Care Unit Patients. 
Am J Infect Dis. 2010; 6 (2): 34- 39

60. Yoshichika, A., Naohiro, S., Keigo, S., et al. Convenient test for screening Metallo- $\beta$-lactamase producing Gramnegative bacteria by using thiol compound. J Clin Microbiol. 2000; 38 (1): 40-43.

61. Bashir, D., Thokar, M. A., Fomda, B. A., et al. Detection of Metallo-beta-lactamase (MBL) producing Pseudomonas aeruginosa at a tertiary care hospital in Kashmir. Afr J Microbiol Res. 2011; 5 (2):164-172.

62. Ghibu, L., Miftode, E., Dorneanu, O., et al. CarbapenemResistant Acinetobacter baumannii Postoperative Meningitis. Jurnalul de Chirurgie Iasi. 2011; 7 (1): 109113.

63. Karaiskos, I., and Giamarellou, H. Carbapenem-Sparing Strategies for ESBL Producers: When and How. Antibiotics. 2020; 9: 61.

DOI: $10.3390 /$ antibiotics9020061.

64. Lautenbach, E., Patel, J. B., Bilker, W. B., et al. Extended-spectrum beta-lactamase-producing Escherichia coli and Klebsiella pneumoniae: risk factors for infection and impact of resistance on outcomes. Clin Infect Dis. 2001; 32: 1162.

65. Biehl, L. M., Schmidt-Hieber, M., Liss, B., et al. Colonisation and infection with extended-spectrum betalactamase-producing Enterobacteriaceae in high-risk patients - Review of the literature from a clinical perspective. Crit Rev Microbiol. 2016; 42 (1): 1-16. 10.3109/1040841X.2013.875515

66. Yusha'u, M., Olonitola, S. O., and Aliyu, B. S. Prevalence of Extended-Spectrum Beta lactamases (ESBLs) Among members of the Enterobacteriaceae isolates obtained from Mohammed Abdullahi Wase Specialist Hospital, Kano, Nigeria. Int J Pure and Appl Sc. 2007; 1 (3): 42 48.

67. Ugah, U. I., and Udeani, T. K. Laboratory survey of extended-spectrum beta-lactamase-producing Enterobacteriaceae from selected tertiary hospitals in southeastern Nigeria. Afr J Clin Exper Microbiol. 2020; 21 (3): 217 - 225. doi.org/10.4314/ajcem.v21i3.7

68. Ejikeugwu, P. C., Ugwu, C. M., Araka, C. O., et al. Imipenem and meropenem resistance amongst ES $\beta \mathrm{L}$ producing Escherichia coli and Klebsiella pneumoniae clinical isolates. Int Res J Microbiol. 2012; 3 (10): 339344.

69. Mukesh, S., Dogra, B. B., Rabindranath, M., et al. Multidrug-resistant Pantoea agglomerans in a patient with septic arthritis- a rare report from India. Int J Microbiol Res. 2012; 4 (6): 263-265.

70. Dutkiewicz, J., Mackiewicz, B., Kinga L., et al. "Pantoea agglomerans: A mysterious bacterium of evil and good. Part III. Deleterious effects: Infections of humans, animals, and plants". Ann Agric Env Med. 2016; 23 (2): 197-205.

71. Yabuuchi, E., Kosako, Y., Oyaizu, H., et al. Proposal of Burkholderia gen. nov; and transfer of seven species of the Pseudomonas homology group II to the new genus, with the type species Burkholderia cepacia (Palleroni and Holmes 1981) comb. nov. Microbiol Immunol. 1992; 36: 1251-1275.

72. Ahlin, A., De Boer, M., Roos, D., et al. Prevalence, genetics, and clinical presentation of chronic granulomatous disease in Sweden. Acta Paediatr. 1995; 84: 1386-1394.

73. Lacy, D. E., Spencer, D. A., Goldstein, A., et al. Chronic granulomatous disease presenting in childhood with Pseudomonas cepacia septicaemia. J Infect. 1993; 27: 301-304.

74. Mardiney, M., Jackson, S. H., Spratt, S. K., et al. Enhanced host defense after gene transfer in the murine p47phox-deficient model of chronic granulomatous disease. Blood. 1997; 89: 2268-2275.

75. Speert, D. P., Bond, M., Woodmann, R. C., et al. Infection with Pseudomonas cepacia in chronic granulomatous disease: role of non-oxidative killing by neutrophils in host defense. J Infect Dis. 1994; 170: 1524-1531.

76. Horsley, A., Jones, A. M., and Lord, R. Antibiotic treatment for Burkholderia cepacia complex in people with cystic fibrosis experiencing a pulmonary exacerbation. Cochrane Database Syst Rev. 2016; 20: 1

77. Govan, J. R. W., Hughes, J. E., and Vandamme, P. Burkholderia cepacia: medical, taxonomic, and ecological issues. J Med Microbiol. 1996; 45: 395-407.

78. LiPuma J. J. Burkholderia cepacia epidemiology and pathogenesis: implications for infection control. Curr Opin Pulm Med. 1998; 4: 337-441.

79. Sarovich, D. S., Price, E. P., Webb, J. R., et al. Variable virulence factors in Burkholderia pseudomallei (melioidosis) associated with human disease. PLoS One. 2014; $11: 9$ (3).

80. Limmathurotsakul, D., Golding, N., Dance, D. A. B., et al. Predicted global distribution of Burkholderia pseudomallei and burden of melioidosis. Nat Microbiol. 2016; 1: Article number: 15008

81. Lipsitz, R., Garges, S., Aurigemma, R., et al. Workshop on Treatment of and Postexposure Prophylaxis for Burkholderia pseudomallei and B. mallei Infection, 2010. Emerg Infect Dis. 2012; 18 (12): e2

82. O'Hara, C. M., Brenner, F. W., Miller, J. M. Classification, identification, and clinical significance of Proteus, Providencia, and Morganella. Clin Microbiol Rev. 2000; 13: $534-546$.

83. Clarke, D. J. "Photorhabdus: shedding light on symbioses". Microbiology Today. 2008; 35 (4): 180-183.

84. Bourafa, N., Chaalal, W., Bakour, S., et al. Molecular characterisation of carbapenem-resistant Gram-negative bacilli clinical isolates in Algeria. Infect Drug Resist. 2018; 11: 735-742. DOI:10.2147/IDR.S150005

85. Coetzee, J., and Brink, A. The emergence of carbapenem resistance in Enterobacteriaceae in South Africa. South Afr J Epidemiol Infect. 2011; 26(4) (Part II): $239-240$.

86. Ho, P. L., Lo, W. U., Yeung, M. K., et al. Complete sequencing of pNDM-HK Encoding NDM-1 carbapenemase from a multidrug-resistant Escherichia coli strain isolated in Hong Kong. PLoS One. 2011; 6(3): e17989.

87. Kanj, S. S., and Kanafani, Z. A. Current concepts in antimicrobial therapy against resistant Gram-negative organisms: Extended-spectrum $B$-lactamase producing Enterobacteriaceae, carbapenem-resistant Enterobacteriaceae, and multi-drug resistant Pseudomonas aeruginosa. Mayo Clin Proc. 2011; 86 (3): 250-259. 